\title{
Observatorio
}

\section{Transición y tendencias de la documentación en televisión: digitalización y nuevo mercado audiovisual}

\author{
Por Eugenio López-de-Quintana
}

\begin{abstract}
Resumen: La documentación y los archivos de televisión se encuentran en un proceso de profunda transformación, tanto de sus funciones y procedimientos de trabajo como de su papel en la organización. Dos elementos confluyen en este cambio: la digitalización completa del flujo de producción y la fragmentación y descentralización del mercado de la producción audiovisual. En este trabajo se identifican los condicionantes, los riesgos y las oportunidades que los profesionales del sector deben canalizar hacia un nuevo modelo de gestión de contenidos audiovisuales basado en la accesibilidad y en la hibridación de funciones y habilidades.

Palabras clave: Archivos de televisión, Documentación de televisión, Mercado audiovisual, Producción audiovisual, Procesos de cambio, Cambios organizacionales, Digitalización, Sistemas integrados de producción digital, Perfil profesional, Tendencias.
\end{abstract}

\section{Title: Transition and trends in television documentation: Digitization and new audiovisual markets}

Abstract: Television archives are engaged in a significant process of transformation involving everyday functions and procedures as well as their overall role in media organizations. The confluence of two elements produces this change: the complete digitization of the flow of production and the fragmentation and decentralization of the audio-visual market. The determining factors are identified, along with the risks and opportunities that media professionals must channel toward the development of a new model of audio-visual content management based on access and the hybridization of tasks and skills.

Keywords: Television archives, Audiovisual information management, Media asset management, Audio-visual market, Audio-visual production, Processes of change, Digitization, Professional profiles, Trends.

López-de-Quintana, Eugenio. "Transición y tendencias de la documentación en televisión: digitalización y nuevo mercado audiovisual”. En: El profesional de la información, 2007, septiembre-octubre, v. 16, n. 5, pp. 397-408.

DOI: 10.3145/epi.2007.sep.01

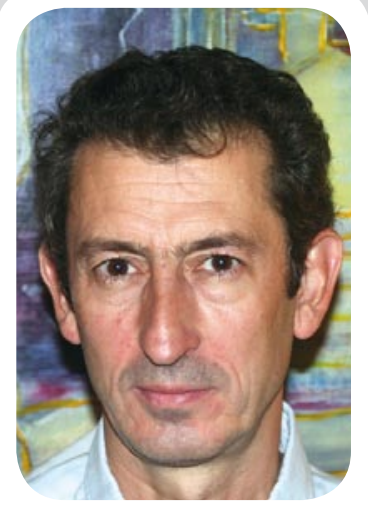

Eugenio López de Quintana Sáenz es licenciado en Geografía e Historia por la Universidad Complutense de Madrid. Desde 1989 dirige el centro de documentación de Antena 3 Televisión y colabora como docente con la Universidad Carlos III de Madrid, Universidad Complutense de Madrid y otras instituciones académicas.

\section{Introducción}

Desde hace varios años se viene observando en los archivos de televisión un cambio de tendencia cuyo alcance todavía parece no estar totalmente definido. Tras un seminario organizado por la FIAT (Federación Internacional de Archivos de Televisión) en 2004 sobre digitalización, Annemieke de Jong recogía los principales elementos de este impacto tecnológico en un esclarecedor texto de conclusiones ${ }^{1}$. Dos años más tarde, en el congreso nacional de la misma organización celebrado en octubre de 2006 en Madrid, algunas de las incógnitas planteadas años antes quedaban todavía en el aire ${ }^{2}$.

Resulta evidente que este sector específico de nuestra profesión se encuentra inmerso en un particular proceso de transición que desembocará a corto plazo en 
Este trabajo explora la incidencia que pueden tener ambos elementos, digitalización y nuevos modelos empresariales, en esta fase de redefinición, asumiendo de antemano que nos moveremos en el terreno de las hipótesis, puesto que el sector comparte más incertidumbres que certezas.

Presentaremos elementos de reflexión con los que cada cual pueda hacer sus propias prospecciones, aparte de aportar a modo de conclusión nuestra propuesta sobre las tendencias a corto y medio plazo en este sector de la documentación, y en última instancia sobre los nuevos perfiles de los profesionales que la ejerzan. Debe tenerse presente que hablamos de un proceso abierto, cuyo resultado final dependerá en gran medida de las iniciativas y la imaginación que cada uno de los actores del mismo podamos aportar.

\section{Documentación en televisión: escenario tradicional}

El modelo de documentación audiovisual del que venimos y que han conocido las principales televisiones de todo el mundo en las últimas décadas se caracteriza por los siguientes elementos:

- Predominio del soporte cinta tanto en la producción como en el consiguiente flujo documental. Esto implica restricciones evidentes en la accesibilidad a los fondos dentro de las organizaciones dada la imposibilidad de multiacceso a un mismo soporte, paliada en el mejor de los casos con políticas de duplicación o copias de seguridad. También exige una administración estricta de sus movimientos o préstamos, actividad con la que fácilmente se ha asociado a los archivos de televisión aunque en ocasiones con una visión excesivamente simplista que no ha favorecido precisamente a su consideración dentro de las organizaciones en la que se integran.

- Concepción del archivo como una entidad física vinculada a infraestructuras complejas de espacio y equipamientos repletos de soportes analógicos de acceso restringido y organización hermética. Podría decirse que esta imagen de los archivos ha preservado su identidad en el ámbito organizacional, pero a veces a costa de un cierto alejamiento y desvinculación del proceso de producción, y con riesgo de segregación del resto de la organización.

- Utilización de sistemas informáticos de gestión documental de carácter referencial, poderosos como herramientas de análisis documental y búsqueda para los documentalistas especializados, pero a menudo un tanto crípticos para el usuario final, y sólo algunas veces conectados al resto de las aplicaciones corporativas.

- Importancia del elemento de conservación y preservación del patrimonio audiovisual dentro de las fun- ciones esenciales de los archivos de televisión, especialmente en el ámbito de las entidades públicas. Aunque resulte paradójico, muchos de los logros obtenidos en este sentido por los archivos de empresas privadas de televisión se deben al prurito profesional de sus documentalistas, que han defendido esta función incluso en una costosa contradicción con los requerimientos básicos de la empresa orientados principalmente a la funcionalidad para la producción.

\section{Tareas documentales}

El papel de los archivos y el rol de los documentalistas de televisión han sido:

- Canalización y registro de los materiales de emisión generados por la cadena o procedentes del exterior, así como de los brutos o grabaciones de cámara, en este último caso con responsabilidad o no en el proceso de selección de estas imágenes para archivo o descarte en función del nivel de desarrollo del flujo documental de cada organización.

- Catalogación o análisis documental de los materiales de archivo, actividad en la que el documentalista ha defendido la ortodoxia como rasgo diferenciador de su profesión, pero con un alto coste en recursos humanos no siempre visible para el resto de la empresa e inalcanzable para compañías de menor envergadura.

En la catalogación se ha mantenido la importancia del control terminológico y de las normas de introducción de datos, si bien no se ha llegado a una normalización equivalente a las reglas de catalogación para los fondos bibliográficos. Esto ha sido debido a la relación que existe entre la descripción a texto libre y las imágenes que se describen, ya que es difícil normalizar la descripción de una imagen por los diversos componentes de contenido que incluye. Sin embargo los documentalistas han mantenido en paralelo mecanismos de indización, aunque con el riesgo de ruido que supone asignar descriptores comunes a un documento audiovisual de varios minutos de duración, o el excesivo esfuerzo que requeriría asignar descriptores a cada una de las unidades documentales con contenido diferenciado, por ejemplo de sólo algunos segundos de duración.

- Intermediación en la búsqueda de imágenes para redactores y equipos de producción, actividad en la que el documentalista se ha movido cómodamente en su papel de llave de acceso a los tesoros acumulados en los archivos a través de su manejo experto de las bases de datos documentales. Esta tarea, en proporción minoritaria en tiempo de dedicación respecto a la catalogación, se ha realizado fundamentalmente en el modo pregunta-respuesta, según el cual el documentalista busca las imágenes solicitadas y ofrece al usuario un listado de resultados para que este elija según su criterio. 


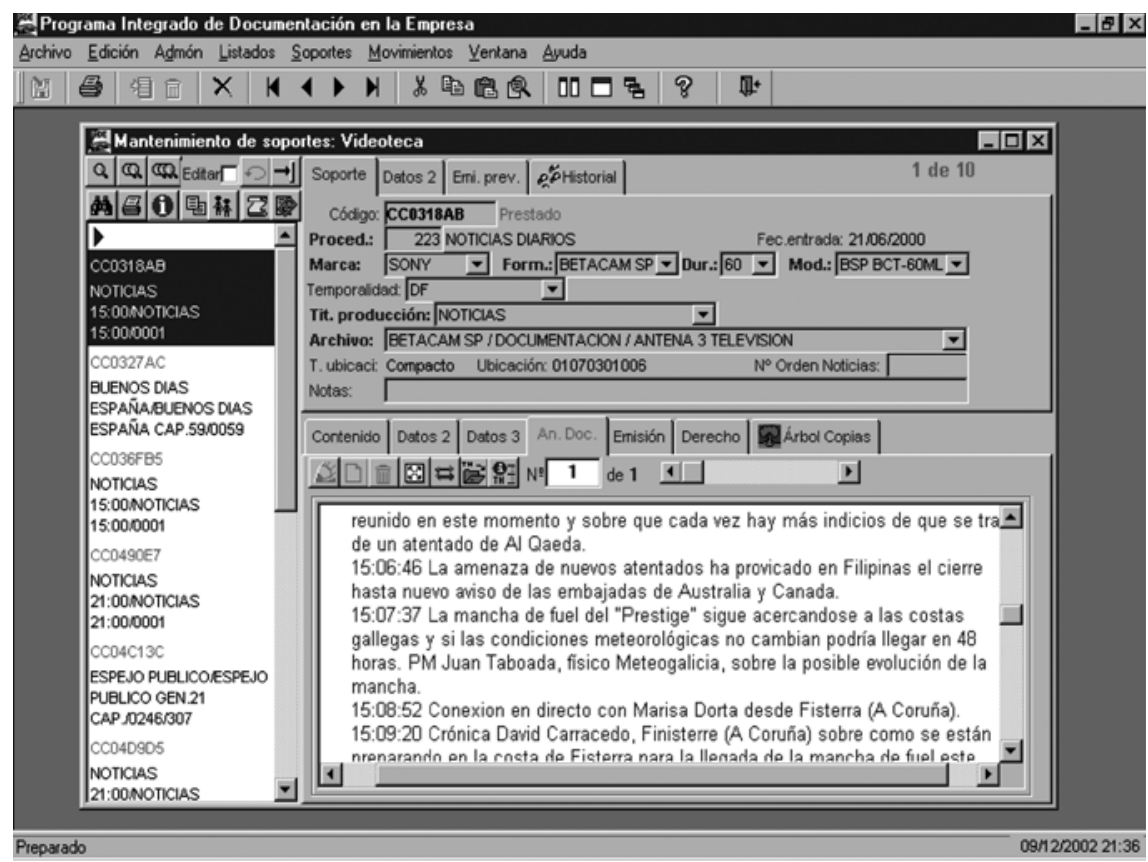

Fig. 1. Ejemplo de catalogación de imágenes con una estructura combinada de base de datos relacional y documental, según el esquema referencial de los sistemas analógicos
La digitalización, que se desarrolla en un entorno híbrido entre ingeniería y sistemas de información, afecta a toda la producción y emisión. Se basa en la utilización de una nueva generación de servidores de vídeo que permiten el almacenamiento de imágenes en ficheros codificados en un formato compatible con los estándares de calidad requeridos para la emisión en televisión. Se sustituye por tanto la cinta como soporte físico de los contenidos audiovisuales, que constituyen la materia prima de la producción en televisión, y en torno a esta posibilidad se desarrollan complejas infraestructuras de software y hardware que reemplazan a su vez los tradicionales equipamientos de edición y emisión basados en el uso de cintas. El impacto es de una gran trascen-

- Para algunos esta forma de trabajo es un tanto desvinculante del proceso completo de la generación de contenidos, ya que salvo excepciones, tanto la selección final del material a utilizar como la elaboración de información queda en manos del redactor. Como alternativa, la progresiva integración de documentalistas en equipos específicos para la producción de programas se ha defendido como vía para su mayor participación en las decisiones sobre contenidos, sin perder sin embargo el componente fundamental de búsqueda.

En este escenario que hemos esbozado someramente destacan las grandes organizaciones de ámbito nacional como $B B C, N B C$, Globo, RAI, ORF, o TVE, entre otras, dotadas con relevantes partidas presupuestarias, importantes dotaciones de recursos humanos, y a menudo dependientes de la administración pública. En España, además de Televisión Española, las televisiones autonómicas primero y las cadenas privadas a partir de 1989 han seguido más o menos similares criterios organizativos, cada una según su envergadura, creando departamentos de documentación centrales para cubrir las necesidades de sus respectivas cadenas.

Tanto unas como otras, las que fueron pioneras cuando todavía se emitía en blanco y negro, y las que posteriormente se han ido incorporando al mercado televisivo, se han viso inmersas en un plazo de pocos años en el complejo proceso de la digitalización. Esto ha proporcionado una cierta uniformidad en cuanto a la identificación de nuevas necesidades y búsqueda de soluciones planteadas por el cambio tecnológico, reduciendo el desfase que existía entre las televisiones de diferente tradición y volumen en cuanto a su posicionamiento en documentación y gestión de la información. dencia funcional y organizacional, y por supuesto alcanza también a los archivos. Veamos en qué modo.

\section{Digitalización}

\section{Digitalización de la señal de vídeo}

Como ya hemos mencionado, la clave del cambio tecnológico reside en la digitalización de la señal de vídeo, que posibilita el acceso multiusuario y simultáneo a los recursos audiovisuales gestionados por sistemas con altas prestaciones para la transferencia de ficheros entre dispositivos. Las principales funciones que veremos de estas aplicaciones se basan en estos conceptos de integración y accesibilidad, que ponen fin a las limitaciones de la cinta como soporte contenedor de imágenes y, en consecuencia, también a la identificación de los archivos con el espacio físico que los aloja.

En lo que afecta concretamente al flujo de producción la digitalización de la señal de vídeo representa:

- Visibilidad y acceso de todos los usuarios a las imágenes con la única limitación de los permisos editoriales o de administración.

- Posibilidad de intervención sobre ficheros ejecutados en modo streaming, lo que permite la edición en tiempo real de señales en curso.

- Disponibilidad de diferentes versiones de un mismo material según el ratio de compresión utilizado, ajustando cada una a cada tipo de utilización: edición en línea, visualización, edición off-line.

- Opciones de selección virtual de cortes de imágenes que no implican movimiento real de materiales hasta su conformación definitiva. 
- Transferencia de imágenes entre dispositivos a una velocidad varias veces superior a la duración del material transferido, ya sea a uno o múltiples destinos.

- Desaparición de la tradicional relación referencial entre metadatos y documento completo: los metadatos son un complemento de las imágenes pero no las reemplazan, puesto que éstas son siempre visibles.

- Facilidades para el intercambio de ficheros entre aplicaciones y sistemas, incluso de diferente ámbito corporativo, dado el alto nivel de estandarización de formatos con las familias MPEG y DV.

Es preciso decir que desde los archivos se vio inicialmente con cierta preocupación la sustitución de la señal convencional de vídeo por su versión digital, contemplando el factor de compresión como un riesgo para la conservación y la durabilidad del documento original. Actualmente las ventajas de la accesibilidad se han impuesto de forma imparable y los archivos ponen el acento en el uso de formatos con bajo nivel de compresión para los materiales de conservación definitiva. Por otra parte, la propia obsolescencia de los formatos de vídeo analógico representa ya hoy un serio problema de accesibilidad por la propia caducidad de los equipamientos de lectura, y en todo caso la migración entre formatos digitales es inmensamente más asumible que el traspaso de imágenes de cinta a cinta.

\section{Edición no lineal}

Las herramientas de edición no lineal permiten enlazar imágenes de una o más fuentes diferentes sin necesidad de que este proceso se realice en el orden secuencial, ya que el ajuste entre los diferentes fragmentos insertados se recalcula automáticamente. Son aplicaciones que reemplazan a las cabinas de edición convencionales sobre cinta con equipos reproductores y un grabadores, en las que es necesario mantener en la incorporación de imágenes el mismo orden secuencial que el de la edición final.

Desde las pantallas de un programa de edición no lineal los operadores pueden acceder a todas las fuentes disponibles en el sistema, ya sean nuevas líneas de grabación, materiales de archivo, otras piezas editadas o cualquier otro tipo de información, como documentos escritos o fonotecas digitales.

Aunque están concebidas inicialmente para la edición de los vídeos destinados a emisión, cubren sobra-

damente las necesidades de los documentalistas en el proceso de transferir las imágenes seleccionadas desde los brutos de grabación y compilarlas en las cintas de archivo. Las compilaciones temáticas realizadas de este modo no están supeditadas al uso de la cinta correspondiente a cada tema hasta que ésta se completa, como ocurre en el mundo analógico. Una vez salvados y alojados en el sistema de almacenamiento digital correspondiente, la organización temática de los ficheros se obtiene a través de los metadatos.

Otra posibilidad es la edición off-line, que consiste en una selección de imágenes procedentes de diferentes ficheros mediante elección de puntos de entrada y salida que actúan como marcas virtuales de código de tiempo. En un momento posterior, el sistema conforma la edición definitiva con o sin modificaciones, importando de los ficheros originales los cortes seleccionados y generando un nuevo fichero.

Esta opción puede ser utilizada por los documentalistas en el servicio de búsqueda de imágenes, ya que permite enviar al usuario una selección virtual de planos eliminando el paso intermedio del contenido referencial o incluso una pre-edición, y transformando de este modo el esquema habitual de pregunta-respuesta que explicamos anteriormente. También puede ser utilizada en sentido inverso por los redactores para determinar qué fragmentos de los brutos de cámara desean conservar en el archivo, incorporando la información necesaria para su identificación.

\section{Catalogación y búsqueda de imágenes}

La catalogación de documentos audiovisuales analógicos constituye en definitiva un intento por repre- 


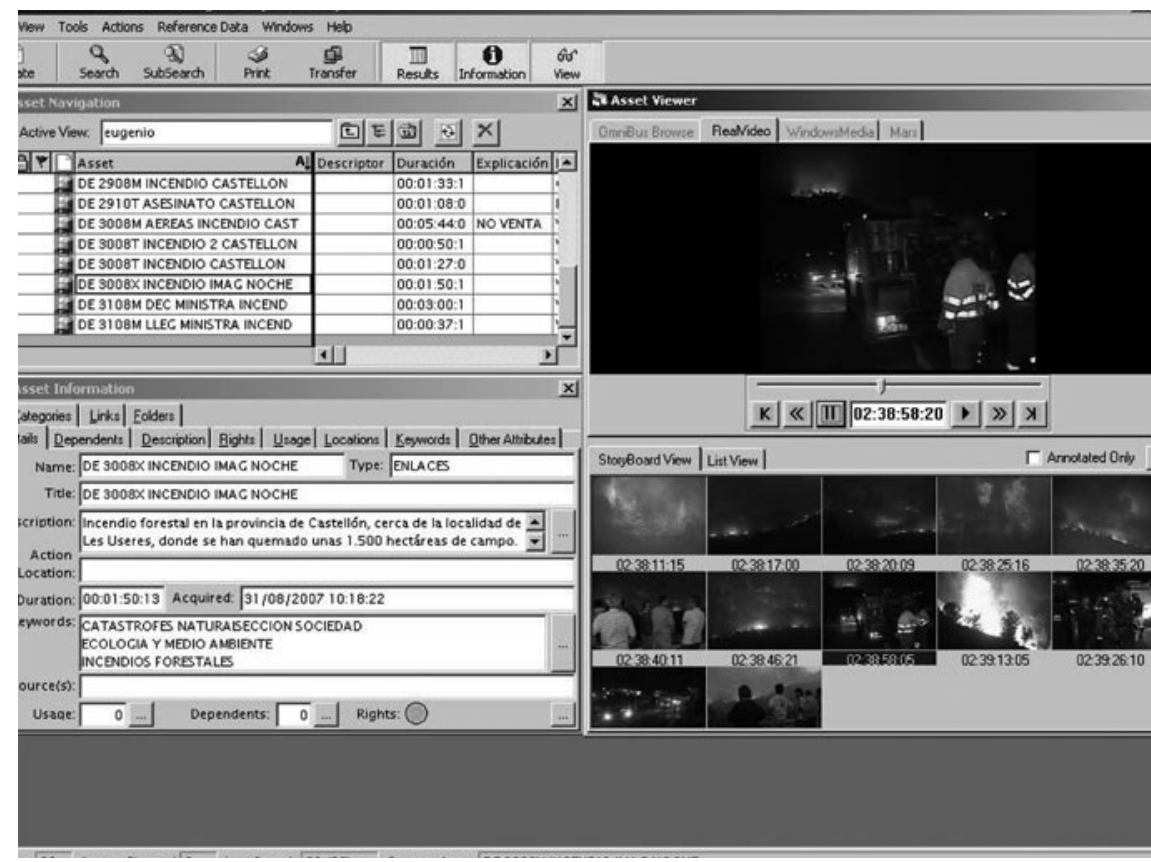

Fig. 3. Pantallas de gestión documental en un sistema integrado digital, en las que se combinan metadatos visuales y de texto, y posibilidad de operar sobre el fichero de video original para recuperar un volumen importante de recursos humanos que puede dedicarse a otros cometidos más relacionados con la gestión y producción de contenidos. Por otra parte, la renuncia a la ortodoxia y a la catalogación exhaustiva viene impuesta en situaciones en las que la disponibilidad de recursos humanos es menor, lo que como veremos es una de las tendencias en el dimensionamiento de las empresas de producción audiovisual. En todo caso, parte importante de las reflexiones sobre el cambio de rol en los documentalistas de televisión gira sobre esta cuestión.

La infinidad de anotaciones, descripciones, clasificaciones $y$ distinto tipo de información que en el mundo analógico los redactores asocian a las cintas de un modo no

sentar textualmente el contenido de una secuencia de imágenes para que pueda ser localizado en una base de datos. En un sistema digital este elemento referencial de recuperación pierde su valor de representación del documento original, puesto que éste puede ser visualizado en tiempo real. No obstante, una secuencia de imágenes no puede todavía ser interpretada de forma automática para obtener elementos de recuperación con los que pueda ser recuperada en una base de datos, y por tanto necesita ser descrita.

La cuestión que se plantea aquí es la diferencia entre catalogar y describir imágenes, pero es un tema delicado porque la catalogación ha sido, como decíamos, una de las señas de identidad de nuestra profesión. Pero si la utilización del lenguaje natural en la descripción de un plano es suficiente para localizarlo, aunque sea con un porcentaje de pertinencia sólo relativamente exitoso, la posibilidad del descarte visual de los planos hallados en una búsqueda puede dar un resultado final bastante satisfactorio. En otras palabras, la ortodoxia en la utilización de normas de catalogación no se vería tan necesaria en el contexto profesional-laboral de una empresa de televisión, y podría ser reemplazada por una tarea ya no tan específica de una única categoría laboral como es la descripción del contenido de las imágenes.

Este tema suscita polémica y opiniones diversas porque puede asociarse a una pérdida de competencias del colectivo de documentalistas de televisión que se ve como peligrosa, y por tanto genera resistencias ante cualquier cambio que pudiera venir por esta vía. Sin embargo, desde otro punto de vista puede considerarse como una posibilidad que aporta la tecnología estructurado, pueden ser incorporadas al flujograma de trabajo con el que se diseñan estos sistemas digitales en torno a los ficheros de vídeo. Es cierto que se trata de información con escasas posibilidades de normalización dada la heterogeneidad del colectivo que la introduce, pero no puede negarse su valor textual de recuperación. Es el caso de los guiones, escaletas, locuciones de los vídeos, minutados y scripts de agencia, o incluso de una transcripción automática del audio de los vídeos cuando el mercado ofrezca un satisfactorio índice de acierto hoy todavía no disponible. También se pueden incluir aquí las transcripciones de las comparecencias oficiales disponibles en los sitios web de ciertos organismos.

\section{"En los sistemas integrados de producción, la asociación de metadatos a un contenido audiovisual no es patrimonio exclusivo de los documentalistas"}

Una hipótesis de trabajo es la de aprovechar toda esta información que se incorpora al sistema en las distintas fases del flujo de producción, complementándola cuando sea preciso con una catalogación más normalizada o una categorización temática por parte de los documentalistas. Para ello es imprescindible disponer de un buen motor de búsqueda capaz de soslayar las dificultades de la recuperación a texto libre, lo que dicho 
sea de paso suele ser una de las carencias más notables que presentan los sistemas digitales de producción que existen en el mercado actualmente. También requiere ciertas concesiones por parte de nuestro colectivo laboral, como ya hemos visto.

Con independencia de quién ejecute la tarea, estos sistemas incorporan interesantes funcionalidades frente a la catalogación referencial tradicional. La más atractiva es la posibilidad de extraer de un fragmento de vídeo fotogramas que permiten identificar visualmente el contenido del documento sin necesidad de ejecutarlo. Estos fotogramas o key-frames pueden mostrarse secuencialmente o en modo de damero, y pueden incorporar sus propios metadatos, algo especialmente útil cuanto mayor es la duración del fichero y por tanto mayor la diversidad de planos con un contenido específico respecto al contenido del documento completo (figura 3). Cada fotograma actúa como un puntero que posiciona el vídeo en el punto exacto en un monitor de visualización o en una pantalla de edición.

La extracción de key-frame es una operación que puede ejecutarse de forma automática por criterios programados de tiempo o incluso de cambio de plano, y que está al alcance de cualquier usuario del sistema gracias a la estructura de capas que permiten estas aplicaciones. Otra funcionalidad atractiva es la de asociar de forma automática un texto a una secuencia a través del código de tiempo, bien se haya éste introducido desde otro módulo, como por ejemplo el de escaleta, o bien se transcriba automáticamente del audio, como decíamos.

Conviene incidir en lo que representa este interfaz básicamente visual para la búsqueda de imágenes, y cómo en la práctica puede paliar los problemas de ruido y por tanto soslayar la necesidad estricta de una catalogación normalizada y exhaustiva. Un usuario puede, tras introducir unos términos de búsqueda y obtener un listado de resultados, visualizar el contenido de keyframe, descartar los títulos no pertinentes, visualizar los seleccionados e importarlos a su línea de trabajo, todo ello sin soltar el ratón. Una forma de trabajo muy conocida por el usuario final, sobre todo si tenemos en cuenta que la práctica totalidad de los usuarios de Google apenas utilizan un par de términos de búsqueda y raramente optan por la búsqueda avanzada.

En esta misma línea, algunos archivos han comenzado a ofrecer a sus usuarios parte de sus fondos digitalizados en modo navegación mediante directorios temáticos organizados jerárquicamente. Los documentalistas puede anticipar de esta manera necesidades que se repiten sistemáticamente y que se conocen como imágenes de recurso: calles, lugares, objetos, personas, perfiles biográficos, etc. La opción de navegación por un árbol visual de recursos es tremendamente útil para el usuario y también para el nuevo documentalista de la era digital, que se reencuentra así con una de las funciones más gratificantes y reconocidas de su componente profesional como es la gestión de contenidos.

En la misma línea está la alternativa de participar en la creación de un gran cuerpo terminológico que soporte la búsqueda de imágenes a texto libre desde la perspectiva de las relaciones semánticas y de las ontologías. Se trata de un campo de acción por explorar y del que el propio mercado del software todavía no ha identificado bien las necesidades en el entorno audiovisual. Si la tecnología lo permite, el redactor de televisión podrá en breve interrogar las bases de datos en lenguaje natural mediante buscadores que interpreten el texto descriptivo de las imágenes a través de una estructura terminológica preestablecida. Documentalistas, filólogos e informáticos comparten en un nuevo ejemplo de hibridación profesional la responsabilidad de estos desarrollos.

\section{Archivo}

Una de las transformaciones más visibles de la digitalización de los archivos en televisión se ha dado en los sistemas de almacenamiento, tanto por la espectacularidad de las comparaciones entre capacidades, como por lo que supone en cuanto a accesibilidad. En la mayoría de los sistemas actuales se da una configuración del almacenamiento a dos niveles, online y near line, debido a los volúmenes de información que se manejan y que en algunos casos pueden alcanzar los centenares de miles de horas en formato profesional.

El almacenamiento online se realiza sobre servidores que permitan albergar hasta unos centenares de horas en línea en los que se alojan las nuevas entradas, los ficheros de trabajo, una selección de archivo y el material de emisión inmediata. Se trata de un espacio limitado en el que se guardan durante algunos días materiales de ciclo de vida corto y una alta proporción potencial de accesos concurrentes. Cíclicamente es preciso liberar espacio eliminando o transfiriendo estos ficheros a librerías digitales, repositorios de archivo a largo plazo cuya capacidad y prestaciones pulverizan literalmente los tradicionales condicionantes de espacio y acceso de los equipamientos para cintas.

Las librerías son dispositivos que contienen decenas de miles de cintas de datos dispuestas en celdas distribuidas periféricamente en sus paredes interiores. Uno o más brazos robotizados recorren las paredes y pueden extraer y trasladar las cintas desde su posición hasta una batería de equipos lectores y reproductores, restituyéndolas luego a su posición inicial. Las librerías se integran como un dispositivo más de todo el sistema, por lo que pueden servir información a cualquiera del resto de dispositivos conectados a la misma matriz. Sumando los tiempos de posicionamiento y transferencia, 


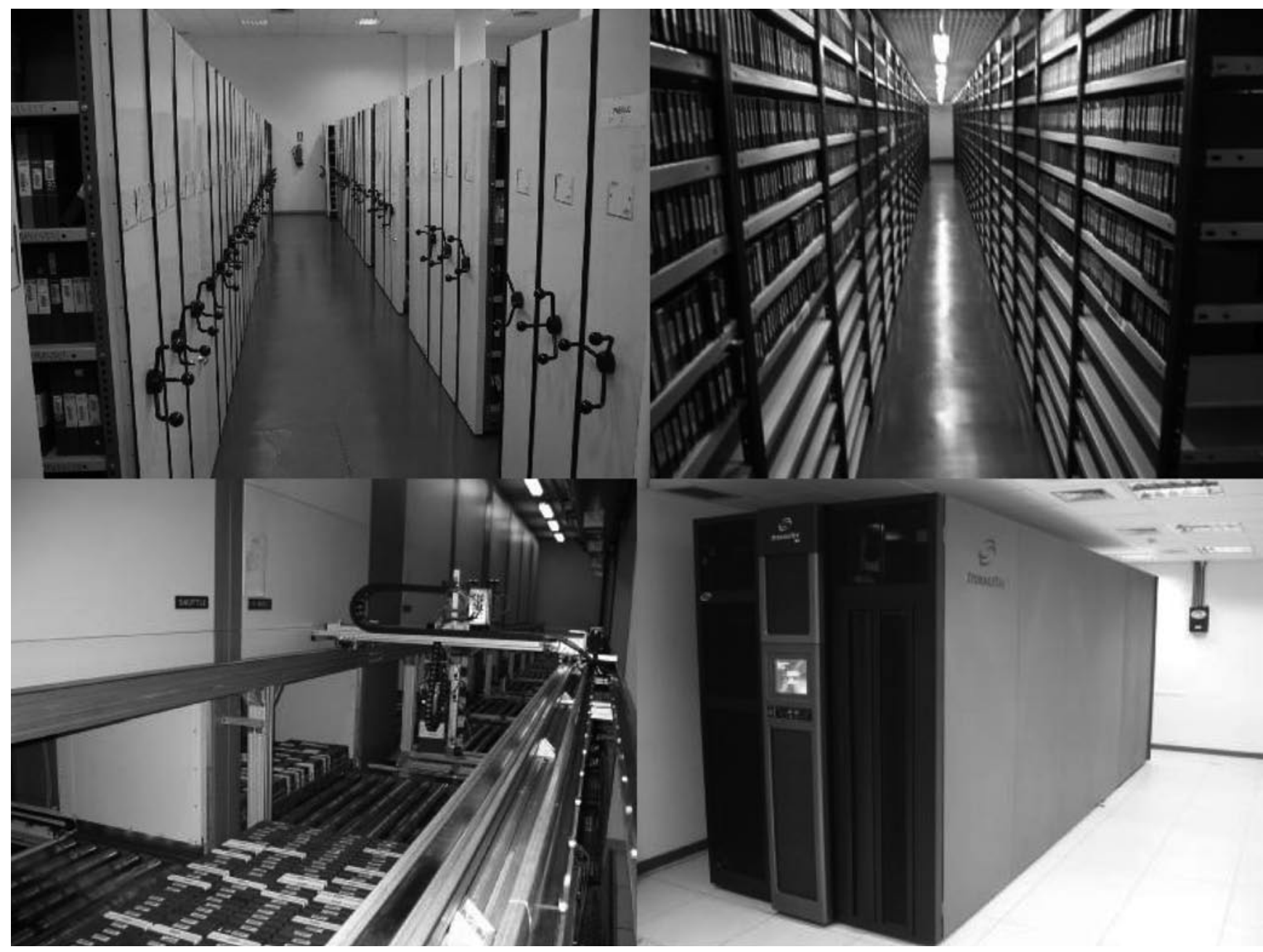

Fig. 4. Diferentes sistemas de archivo convencional de cintas y librería digital Storagetek SL-8500, con capacidad para varios cientos de miles de horas de vídeo en formato profesional

las imágenes viajan a una velocidad proporcionalmente varias veces menor a la de su duración en tiempo real. De ahí viene el término near line, "casi”" en línea.

En el mercado existe una gran diversidad de productos, tanto de modelos de librería como de formato de cintas, y no es sencillo generalizar rendimientos y parámetros. Pero en líneas generales, la capacidad de almacenamiento de las cintas está en un rango de 200 a $800 \mathrm{~GB}$, lo que representa entre 20 y 100 horas de capacidad de vídeo en formato broadcast (profesional), también variable en función de los parámetros de compresión. Una habitación de sólo diez metros cuadrados puede así albergar hasta 1.000.000 de horas de vídeo, el equivalente en espacio a unos 3.000 metros cuadrados de superficie ocupada por mobiliario compacto. Estos dimensionamientos no son sin embargo estáticos, ya que el mercado de las cintas de datos viene ofreciendo regularmente nuevos modelos de mayor capacidad. Ya están anunciadas cintas de hasta 400 horas, el equivalente a unos 12 metros lineales de estantería, y a medio plazo se habla ya de los soportes holográficos, que multiplicarán varias veces estas capacidades (figura 5). Las propias librerías incluyen automatismos para la compactación sistemática de las cintas ocupadas y también para la migración de imágenes entre cintas, lo que permite programar transferencias masivas sin interrumpir la operativa diaria.

\section{http://www.sun.com/storagetek/tape.jsp}

http://www.quantum.com/Products/TapeLibraries/ index.aspx

http://www.sonybiz.ca/solutions/SearchResults. do?keyword=petasite

Veamos qué representa para el flujo de producción esta nueva generación de archivos a los que ya no es preciso desplazarse para pedir una cinta en préstamo.

- Tendencia natural de los redactores a priorizar la utilización de imágenes alojadas en los almacenamientos digitales frente a los archivos en cinta, cuya mera manipulación resultará anacrónica a corto plazo. Los archivos tienen que evitar esta "brecha digital" planificando políticas de digitalización retrospectiva con criterios de accesibilidad y conservación, pero también de rentabilidad. 
“El archivo terminará siendo un concepto abstracto de accesibilidad, un recurso más dentro del sistema digital"

- Eliminación progresiva, dentro de la cultura organizacional de las televisiones, de la identificación entre el archivo y las instalaciones que lo alojan. La ubicación de las librerías es irrelevante para el usuario mientras se garantice el acceso a los ficheros seleccionados, incluso todo el almacenamiento puede ser subcontratado a empresas de servicio externas.

- Reducción paulatina de muchas de las tareas asociadas al alojamiento y movimiento de las cintas: etiquetados, préstamos, ubicaciones, desplazamientos por los pasillos. La intermediación entre el usuario y el archivo por parte del colectivo profesional encargado durante años de conservarlo y custodiarlo, dejará de ser necesaria. Esto exige políticas de reclasificación profesional de los colectivos afectados, cuya actividad puede parcial y progresivamente reconducirse hacia otras tareas derivadas del tránsito hacia la digitalización.

- El archivo se concebirá como un proceso dentro del flujo completo de producción digital, basado en actuaciones corporativas orientadas a la conservación y a la accesibilidad. Pero aunque varía el soporte, permanece la necesidad de políticas de archivo administradas con criterio profesional de preservación. El principal riesgo es que la organización no contemple esta necesidad, fascinada por las aparentemente ilimitadas posibilidades de los archivos digitales en las fases de arranque. Nos corresponde a nosotros evitarlo, reubicando la función del archivo en la nueva filosofía organizacional del entorno digital.

- Aparición de nuevos perfiles profesionales con hibridación de funciones entre la gestión de contenidos y la administración de sistemas, responsables de la gestión de los distintos activos dentro del sistema en relación con los diferentes y simultáneos flujos de trabajo.

- Horizonte asegurado de migraciones permanentes de contenidos digitales de archivo entre soportes y formatos, bien por aparición de nuevas cintas con mayores prestaciones o bien por obsolescencia de los formatos.

\section{Media asset management}

No podemos finalizar este apartado sin hacer referencia a los media asset management o MAM, término clave en cualquier implantación de sistemas digitales integrados de producción, que podríamos traducir de forma aproximada como "sistemas de gestión de me- dios" o "sistemas de gestión de activos audiovisuales". Son las aplicaciones que centralizan el control de todos los elementos de software y hardware del sistema: servidores, librerías, estaciones de edición, escaletas de emisión, líneas de entrada y salida, etc.

Aunque es un término de una curiosa ambigüedad tanto en la literatura técnica como en el propio lenguaje de los implantadores de proyectos, representa bien la filosofía de este nuevo escenario de trabajo que generalizamos como "digitalización", a través de los conceptos de integración y accesibilidad. La digitalización de toda la cadena de producción de una televisión es un complejo engranaje de elementos integrados entre sí, en el que tanta importancia tiene el aporte tecnológico de los mismos como el diseño y desarrollo de los nuevos flujos de trabajo que se requieren. El MAM administra cualquier operación relacionada con cada uno de los ficheros del sistema y garantiza la integridad de la base de datos a través de los innumerables procesos de adquisición, edición y emisión de imágenes que se ejecutan en una televisión de forma permanente. También tiene el control de todas las transferencias entre dispositivos y del flujo de vídeo y datos dentro del sistema.

Annemieke de Jong afirma: "MAM no es un sistema, ni un departamento, ni un archivo, puesto que constituye un planteamiento filosófico fundamental de enormes proporciones, actualmente en marcha, que tiene por objeto gestionar las ideas que los medios de comunicación manejan, desde que surgen hasta su emisión". Esta idea subyace en todas las ventajas, pero también en los riesgos y en las dudas que se suscitan en torno a las funcionalidades de los archivos en los nuevos escenarios de producción digital:

- Con los MAM se difuminan las fronteras entre las diferentes áreas corporativas de la empresa. El concepto y las herramientas de la digitalización adquieren un gran protagonismo en sí mismos, concretado en la gran versatilidad de las nuevas posibilidades que se ofrecen.

- Muchos de los flujos de trabajo convencionales se redefinen totalmente, y en este camino los archivos necesitan reubicarse dentro del nuevo proceso de producción. Como la responsabilidad de los MAM recae en las áreas de ingeniería y sistemas, es imprescindible mantener una vinculación organizativa con estas áreas en las fases de diseño e implantación para garantizar una correcta cobertura de las funciones requeridas.

- Existe un considerable desfase entre las posibilidades potenciales de estos nuevos sistemas y las obtenidas en el producto final. En el complejo camino hasta la entrada en explotación muchas expectativas quedan postergadas para futuras fases de desarrollo, y a menudo los más básicos requerimientos del flujo documen- 


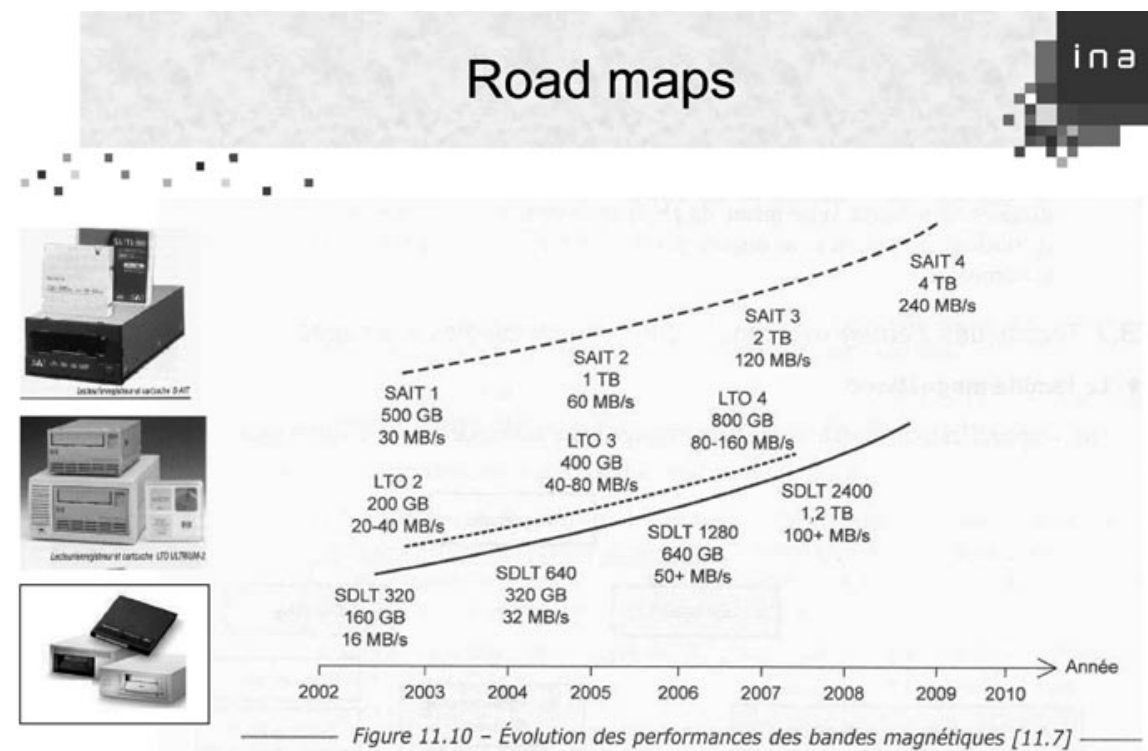

Fig. 5. Road map o gráfico de evolución de los formatos de cinta de datos (Jean Varra)

http://www.vsn-tv.com/en-up/ archive.htm

http://www.dalet.com/MediaLibrary

http://www.createcna.com/cellarium.html

http://www.activamultimedia. $\mathrm{com} / \mathrm{am} / v_{-}$portal/apartados/pl_ productos.php? $t e=191 \& i d m=151$

\section{Nuevos modelos de producción audiovisual}

Durante los últimos años se ha producido en España un considerable aumento en el número de operadores y canales de televisión. Las televisiones locales, las plataformas

tal no están inicialmente contemplados. Tres tipos de carencias son las habituales: en las prestaciones de los productos existentes en el mercado, en la identificación de las necesidades de los archivos y documentalistas, y en el desarrollo de la implantación.

- La arquitectura y la filosofía de los MAM conduce a la descentralización. Cada usuario o grupo de usuarios accede a las aplicaciones y a sus propios espacios de almacenamiento, trasladando al sistema la misma autonomía que antiguamente se tenía al trabajar con cintas dentro de una cabina de edición o en su mesa de trabajo. Reaparece así el riesgo de interrupción del flujo documental tan temido por los archivos, según el cual se priman las necesidades individuales o de áreas concretas y puede no garantizarse el aporte colectivo de imágenes a un fondo documental único de acceso corporativo. El término inglés bottom drawer expresa gráficamente este riesgo y seguro que resulta familiar a los documentalistas de televisión

- También se modifican los tipos y el alcance de los fallos técnicos cuando éstos se producen. En el mundo analógico estas situaciones tienen un carácter más local: se daña una cinta, falla un equipo o hay una caída del sistema informático. Las incidencias técnicas en los $M A M$ tienen un mayor alcance, los daños en una cinta de datos pueden inutilizar varios centenares de horas de archivo, y se pueden producir pérdidas o fallos irrecuperables en ficheros de vídeo. Se imponen criterios de redundancia en los materiales de archivo, lo que por otra parte resulta más viable y económico que con los fondos en cinta, y además son tareas programables para su ejecución automática dentro del sistema.

http://www.ardendo.com $/$ ?page $=$ products \& subpage $=$ ardome

http://www.broadcast.harris.com/television/dam/ digitales, los canales para televisión digital terrestre y las últimas dos televisiones en abierto de ámbito nacional constituyen un amplio espectro de ventanas que demandan la creación de producto audiovisual para rellenar las respectivas parrillas.

La principal característica común de todos estos nuevos negocios es la reducción de su dimensionamiento en comparación con las grandes televisiones aparecidas en la década de los 80 , autonómicas y privadas, y por supuesto con Televisión Española. Esta menor envergadura responde a una reducción de la infraestructura de producción en favor de la externalización de la producción y una política de compra de productos para emisión a otros proveedores en los mercados nacional o internacional. Por tanto, paralelamente al aumento de operadores también se ha producido un crecimiento de las empresas nacionales de producción audiovisual, que venden sus formatos a los operadores de televisión o reciben encargos para producir programas que éstos puedan emitir.

Esta situación tiene varias consecuencias para el sector laboral de la documentación audiovisual.

- Se ralentiza o se estanca el crecimiento de las plantillas de recursos humanos de las grandes cadenas de televisión, en favor de políticas de contratación temporales cuya duración está ligada al ciclo de producción del programa para el que se contrata. Estas contrataciones pueden originarse tanto en las propias cadenas como en las empresas productoras, según sean las condiciones del contrato de producción.

Se buscan profesionales familiarizados con el ciclo de producción de un programa, habituados no sólo a la búsqueda sino también al análisis documental de imágenes y a los criterios de selección de brutos. Se requieren conocimientos en el manejo de equipos de edi- 
ción de vídeo y ahora también de los fundamentos de las herramientas equivalentes en los sistemas digitales. Asimismo es imprescindible un cierto conocimiento de las aplicaciones y las políticas de trabajo de la organización específica en la que se va trabajar, especialmente cuando el documentalista es contratado para encargarse del ciclo documental completo. Es muy importante también la experiencia en la atención a usuarios y sobre todo la capacidad de incorporación inmediata a equipos de trabajo cambiantes en cada contrato

- Las productoras por su parte han ido creando estructura en función de la demanda de producción y según su respectivo tamaño, lo que incluye la necesidad de gestionar sus propios fondos documentales. Se trata normalmente de pequeñas áreas a veces unipersonales, a menudo con convergencia de funciones en producción y redacción aparte de las propias de documentación, y en las de más reciente creación concebidas desde su origen sobre sistemas digitales. Modelos similares también se dan en los portales y canales web de televisión, en los que la hibridación de perfiles es aún mayor.

En este tipo de organizaciones priman la rentabilidad y la accesibilidad en la gestión de contenidos. Los criterios de catalogación son menos exhaustivos y poco normalizados, como consecuencia también de que las dotaciones de recursos humanos suelen ser reducidas. Además generan una constante oferta laboral en condiciones habituales de temporalidad y rotación sobre distintos proyectos en función de los diferentes calendarios de producción de programas para terceros.

- A corto o medio plazo es probable que también consolide el perfil profesional del buscador de imágenes según el modelo de los film research que operan en otros países, y cuya demanda ya ha comenzado a detectarse. Se trata de expertos en rastreo de archivos audiovisuales que son contratados para el suministro periódico de un determinado volumen de imágenes para las necesidades de producción de un programa. Es una necesidad que encaja bien con el modelo mencionado de fragmentación de la producción audiovisual en diferentes empresas, las cuales lógicamente no disponen de archivos históricos dada su relativamente reciente aparición. Se prioriza la disponibilidad y la posibilidad de desplazamiento, el conocimiento de idiomas para el acceso a archivos internacionales, y por supuesto la familiaridad con los criterios habituales del uso de imágenes en televisión.

- En esta misma línea de los trabajadores autónomos no es de extrañar que las tareas a contratar se extiendan también al resto de funciones del documentalista de televisión en todo el proceso documental, en especial a la catalogación e indización. La externalización de servicios y las favorables condiciones para el teletrabajo en documentación audiovisual que aportan las nuevas herramientas digitales, hacen idónea esta fórmula para las empresas que han optado por una reducción de estructura y un dimensionamiento en función de sus necesidades de producción.

\section{Transición y tendencias: conclusiones}

El futuro inmediato de la documentación y los archivos de televisión pasa necesariamente por una redefinición de sus funciones y de su posición en la organización. El nuevo escenario viene fuertemente determinado por la digitalización integral del proceso de producción y por la descentralización de la producción televisiva en empresas de estructura y dimensionamiento reducidos. A modo de conclusión, éstas podrían ser algunas de las principales ideas y posibilidades sobre las que se articula este cambio:

- Los archivos de televisión cambiarán su identidad física dentro de la organización por su posición como proceso dinámico y descentralizado integrado en el flujo digital de producción.

- La catalogación dejará de ser elemento predominante en el rol del documentalista audiovisual, reemplazada por la tarea de integración de los metadatos introducidos de forma descentralizada a lo largo del flujo de trabajo.

- La gestión electrónica de fondos documentales resultará probablemente más compleja que la administración de los archivos convencionales, y también lo será garantizar procedimientos y criterios de normalización dentro de los nuevos sistemas digitales.

- Se reducirá el papel de intermediación a medida que se desarrollen las habilidades de búsqueda de los usuarios del sistema, aunque probablemente se mantenga este rol en procesos de búsqueda complejos y cuando el documentalista tenga mayor implicación en la elaboración del contenido final.

- Los documentalistas tendrán competencias fundamentales en la anticipación de necesidades de los usuarios, bien haciendo navegables los fondos de archivo mediante estructuración temática de los recursos de visualización, bien con el desarrollo de motores de búsqueda y cuerpos terminológicos que potencien el uso del lenguaje natural en la interrogación de las bases de datos.

- Se mantendrá el componente de conservación patrimonial y preservación de la memoria audiovisual a largo plazo como seña de identidad de los archivos, cuyo formato digital plantea ahora algunas incógnitas y esta supeditado a constantes migraciones entre formatos para garantizar su accesibilidad. 

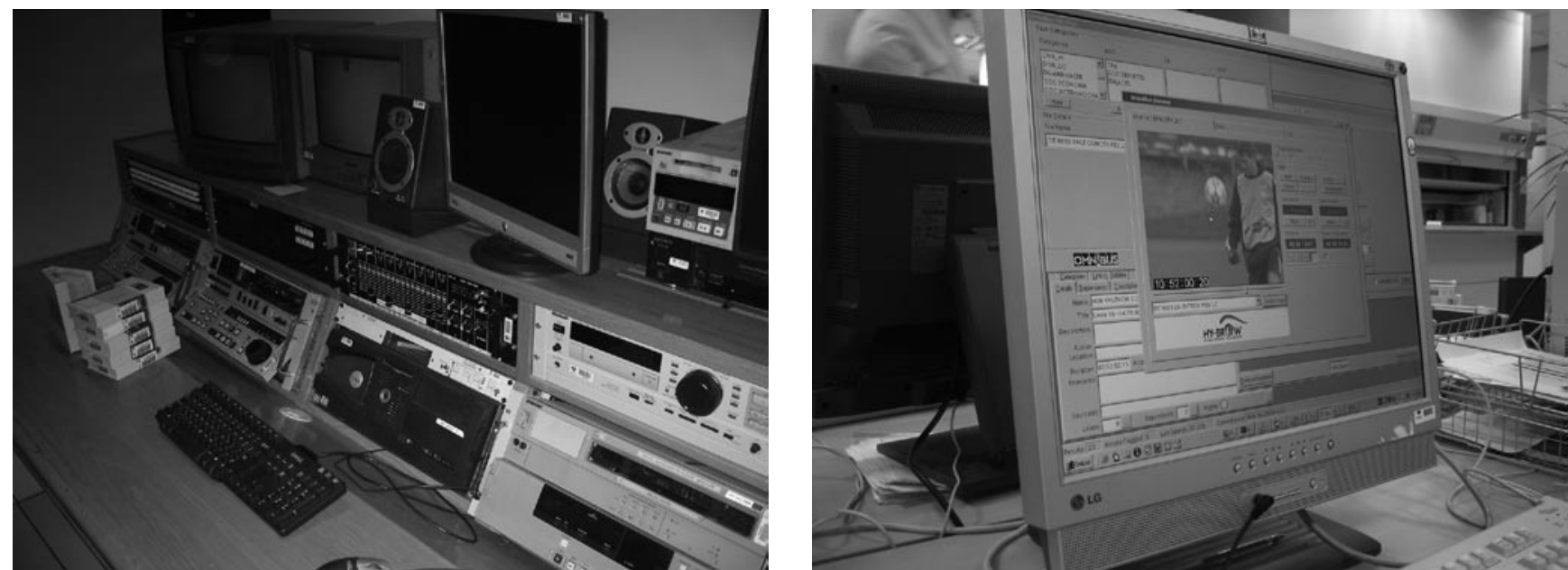

Fig. 6. Cabinas de visionado y edición en cinta; y estación de trabajo en un sistema integrado de gestión

- También será competencia de los archivos salvar el abismo que se abre entre los fondos históricos en soportes analógicos y los entornos digitales de producción, impulsando políticas de digitalización retrospectiva y procedimientos para transferir a demanda imágenes desde los fondos en cinta hacia el flujo de producción.

- El mantenimiento a ultranza de las tradicionales fronteras de la documentación como profesión no tendrá cabida en el modelo de trabajo de la televisión digital. En su lugar se impone la permeabilidad hacia otras categorías profesionales de la organización, sustituyendo el temor al intrusismo por una mayor aceptación de la hibridación de funciones. La nueva figura del media manager o gestor de medios, encargado de supervisar el ciclo de vida y permanencia de los materiales en los diferentes sistemas de almacenamiento, es un ejemplo de ello.

- La temporalidad en el modo de contratación de las empresas privadas de producción se impone frente a la creación de plantillas estables para adecuarse a la propia temporalidad de la producción de programas. El documentalista de televisión debe saber situarse en este nuevo mercado, explotando la rotación de contratos como formación constante y asegurando su continuidad laboral mediante el desarrollo de un perfil cada vez más engranado con los nuevos modos de producción.

- Nuevas fórmulas de trabajo a través de la facturación de servicios están aún por explorar en este sector, aplicables a la búsqueda de imágenes, catalogación o digitalización de archivos. La digitalización también permite concebir experiencias de teletrabajo, haciendo accesible a distancia el visionado de ficheros y la transferencia de metadatos.

Para terminar, conviene recordar que nos hallamos en una fase de tránsito. Muchas productoras y televisiones no disponen de herramientas de digitalización, y en algunas donde sí existen sólo se utilizan en una parte del total de su producción. Millones de cintas de múltiples formatos se alojan en los archivos de todo el mundo, algunos con grave riesgo de obsolescencia, y sólo un pequeño porcentaje de los fondos está digitalizado. Todavía en algunas empresas del entorno audiovisual no existe servicio de documentación ni archivo, o bien sus funciones están totalmente desvirtuadas.

La transición es una zona turbulenta, en la que se manejan expectativas e incertidumbres en un esfuerzo colectivo de transformación y también de resistencia a que ésta se produzca. En el caso de la documentación en televisión el cambio hacia un modelo diferente y una distinta concepción de su lugar en la organización ya está en marcha. El resultado no depende sólo de un determinado cambio tecnológico, sino de la implicación de los profesionales del sector en la redefinición de procesos y procedimientos de trabajo para sacar el máximo partido de las nuevas herramientas a su disposición.

\section{Notas}

1. Changing scenarios, changing roles. Media management in the digital era. Proceedings of the Media management seminar changing roles, changing scenaries. Amsterdam $19^{\text {th }}-20^{\text {th }}$ of March 2004. Organised by FIAT/ IFTA Media Management Commission and the FIAT/IFTA.

2. Conservar y difundir nuestro patrimonio audiovisual. La era de los archivos televisivos. Madrid, 27-31 de octubre, 2006, FIAT/IFTA y Universidad Carlos III de Madrid.

\section{Bibliografía}

Archives in digital broadcasting. EBU/UER, 2003, 41 pp. http://www.fiatifta.org/restricted/standards/UER_Informe_Es.pdf

Bailac, Montserrat; Catalá, Montserrat. "El documentalista audiovisual". En: El profesional de la información, 2003, vol. 12, n. 6, nov.-dic., pp. 486-488.

Caldera-Serrano, Jorge; Zapico-Alonso, Felipe. "Estructura y funcionamiento del servicio de información audiovisual en televisión”. En: El profesional de la información, 2004, vol. 13, n. 2, marzo-abril, pp. 130-140.

Caldera-Serrano, Jorge; Zapico-Alonso, Felipe. "Seen and heard: duality at the access points to television databases". En: Aslib proc., 2006, vol. 58, n. 4 , pp. 304-315. 
http://www.emeraldinsight.com/Insight/viewContainer.do? containerType= JOURNAL\& containerId $=11387$

Esteve, Pablo. "Robotic storage libraries". En: Broadcast engineering, 1 Sept. 2003.

http://broadcastengineering.com/mag/broadcasting_robotic_storage_libraries/

Gilmer, Brad. "Media asset-management systems". En: Broadcast engineering, 1 Aug. 2003.

http://broadcastengineering.com/ar/broadcasting_media_assetmanagement_systems/index.htm

Hidalgo, Paloma. "La formación de los profesionales de la documentación audiovisual. En: Conservar y difundir nuestro patrimonio audiovisual. La era de los archivos televisivos. Madrid, 27-31 octubre, 2006, FIAT/IFTA y Universidad Carlos III de Madrid.

López-de-Quintana, Eugenio. "Expectativas y realidad en la cobertura de necesidades de documentación y archivo en los MAM”. En: Conservar y difundir nuestro patrimonio audiovisual. La era de los archivos televisivos. Madrid, 27-31 octubre, 2006, FIAT/IFTA y Universidad Carlos III de Madrid.

Montagnuolo, Maurizio. Introduzione alle tecniche di image analysis per la classificazione automatica degli archivi audiovisivi. En: Elettronica e telecomunicazione, 2005, n. 1, agosto.

Varra, Jean. "Digital solutions for preservation. State of the art". Conservar y difundir nuestro patrimonio audiovisual. La era de los archivos televisivos. Madrid, 27-31 octubre, 2006, FIAT/IFTA y Universidad Carlos III de Madrid.

Vázquez, María-Luisa. "El factor humano en un mundo de ficheros". Conservar y difundir nuestro patrimonio audiovisual. La era de los archivos televisivos. Madrid, 27-31 octubre, 2006, FIAT/IFTA y Universidad Carlos III de Madrid.

Wright, Richard. "What archives want. The requirements for digital technology”. En: EBU technical review, 2006, October.

\section{El profesional de la información}

\section{Precios 2008}

http://www.elprofesionaldelainformacion.com

\section{REVISTA IMPRESA + ACCESO ONLINE (ISSN 13866710 + ISSN-e 1699-2407)}

Suscripción normal:

Tarifa reducida para personas individuales*:

* exclusivamente a domicilios particulares

Coste adicional de correo aéreo:

- Europa (menos España)

$30 €$

- Américas y resto del mundo
$147,2 €+$ IVA $=153 €$

$75 €+$ IVA $=78 €$

Acceso online (incluye 1 clave de acceso: username-password)

Claves de acceso adicionales:

$85 €+$ IVA $=88,4 € /$ cada una

\section{NÚMERO SUELTO ACTUAL O ANTIGUO}

Número suelto actual o antiguo:

$$
25 €+\text { IVA }=26 €
$$

Coste adicional de correo aéreo:

- Europa (menos España)

- Américas y resto del mundo

\section{SÓLO ACCESO ONLINE ii NUEVO !!}

Únicamente acceso a versión electrónica

NOTAS:

1. De cara a las tarifas de 2009 , la editorial está estudiando la introducción de suplementos de precio según el número de bibliotecas existentes en cada institución.

2. El IVA aplicado es España es del $4 \%$

3. El período 1992-2006 es de acceso libre y gratuito desde nuestra web: http://www.elprofesionaldelainformacion.com 